\title{
BIOPODER E CUIDADO DE SI NO PENSAMENTO DE MICHEL FOUCAULT
}

\author{
Aldo AMBRÓZIO ${ }^{1}$ \\ Universidade Anhembi Morumbi \\ aldoamb@uol.com.br \\ Paulo Alexandre Cordeiro de VASCONCELOS ${ }^{2}$ \\ Universidade Potiguar/UNP/RGN \\ paulovas@gmail.com
}

\begin{abstract}
Resumo: Levanta questões relativas à constituição das subjetividades contemporâneas acompanhando, no pensamento de Michel Foucault, a transição de sua pesquisa entre a problematização dos regimes de obediência, por meio da explicitação do conceito de Biopoder, e a abertura sobre uma possibilidade de liberdade ética, por meio da exploração do conceito de cuidado de si no pensamento antigo e no pensamento helenístico. Trata-se de um estudo teórico ancorado em pesquisa bibliográfica que, como resultado, aponta para uma problematização de si diversa da proposta pelas tutelas contemporâneas.
\end{abstract}

Palavras-chave: Bipoder. Disciplinas. Biopolíticas. Cuidado de si e processos de subjetivação.

\begin{abstract}
It stands up relative questions to the constitution of the contemporary subjectivities accompanying, in the thought of Michel Foucault, the transition of his inquiry between the problematization of the obedience regimes, through the set out of the concept of Biopower, and the opening on a possibility of freedom ethics, through the exploration of the concept of care of the self in the ancient thought and in the hellenisthic thought. It the question is a theoretical study anchored in bibliographical inquiry that, like resulted, points to a different problematization of the self that proposal for the contemporary protections.
\end{abstract}

Key-words: Biopower. Diciplines. Biopolithics. Care of the self and subjetivation process.

\section{Introdução}

O texto que ora propomos busca transitar entre os conceitos de Biopoder e cuidado de si na obra de Michel Foucault. Para isso, o viés que buscaremos traçar no decorrer de nossas digressões visa levantar a tensão entre a perspectiva final da obra de Foucault ${ }^{3}$, em que claramente emerge uma preocupação com a processualidade constitutiva dos modos de vida, e

\footnotetext{
${ }^{1}$ Mestre em Administração pela Universidade Federal do Espírito Santo. Doutorando em Psicologia Clínica pela Pontifícia Universidade Católica de São Paulo. Bolsista pela CAPES. É professor convidado da Universidade Anhembi Morumbi. Possui artigos publicados em anais de congresso nacionais e internacionais. É pesquisador nos temas: poder; subjetividades e sua relação com o contemporâneo. Email: aldoamb@uol.com.br.

${ }^{2}$ Doutor pela Eca USP, com a obra Baudrillard do Texto ao Pretexto-1999, Alexa Editorial 2004, tendo outras obras publicadas na área de Comunicação, consumo e imaginário, bem como artigos em publicações Nacionais e Internacionais; docente da Anhembi Morumbi, professor credenciado - convidado Eca USP na disciplina Consumo Estratificado da Produção Cultural. Pesquisador nas áreas: Comunicação Consumo, Moda e imaginário. Email: paulovas@gmail.com.

${ }^{3}$ Trata-se do momento caracterizado por alguns comentaristas como Roberto Machado, Salma Tannus Muchail, entre outros, como o momento ético, ou seja, em que Foucault dá relevância, por meio do estudo da prática do cuidado de si entre os Antigos e os Romanos do primeiro século cristão, aos exercícios de constituição de si que tenham como princípio a liberdade e não a tutela.
} 
suas preocupações no momento anterior, no qual a atenção do filósofo voltava-se para os modos de intervenção concreta sobre os corpos denominados relações de poder.

A questão que então tentaremos responder no decorrer do texto versa sobre o que se passou com o pensamento do filósofo no decorrer dos oito anos entre a publicação do primeiro volume da História da Sexualidade em 1976 e os dois volumes posteriores cuja publicação se deu em 1984 e como essa perspectiva final de sua obra pode nos auxiliar nos exercícios constantes de nos tornarmos seres éticos.

Assim, apresentaremos o texto em meio a três perspectivas: inicialmente faremos a exposição dos estudos do autor sobre o Biopoder; posteriormente, apresentaremos algumas considerações sobre a transição dessa perspectiva para o momento final de sua obra, para por fim, elucidarmos o conceito de cuidado de si e suas contribuições na construção de um modo de individuação contemporâneo.

\section{Biopoder}

Foucault (1988) nos apresenta duas maneiras distintas de exercício de poder: uma que tomaria a vida como direito próprio do soberano e que teria como princípio atuante o fazer morrer e deixar viver - modo que marcaria todo o período do absolutismo monárquico - e uma que tomaria a vida como elemento gestável e que teria como princípio atuante o fazer viver e deixar morrer - modo que marcaria as políticas dos Estados ocidentais no alvorecer da Modernidade.

A partir desses modos de apreensão da vida pelo poder poderíamos marcar maneiras distintas de lidar com os fenômenos próprios ao vivente: o primeiro exercício estaria ligado a um tipo de sociedade cujo funcionamento estaria relacionado com a extração das forças próprias ao sócius, assim, os corpos, o tempo, as mercadorias e, enfim, a vida seriam, para o soberano, elementos que ele poderia confiscar como direito de propriedade; o segundo exercício estaria relacionado com um tipo de sociedade em que faria mais sentido a majoração e utilização das forças do que sua extração pura e simples por meio de uma espécie de direito monárquico.

Portanto, de um lado teríamos um direito de morte em função do qual os corpos dos súditos, assim como, os bens de um território poderiam ser requeridos pelo soberano sempre que o mesmo se sentisse ameaçado ou quando as leis regentes de seu território fossem maculadas. 
De outro, teríamos o exercício de um poder sobre a vida, cujo princípio norteador, estaria mais próximo a "[...] funções de incitação, de reforço, de controle, de vigilância, de majoração e de organização das forças que lhe são submetidas: um poder destinado a produzir forças, a fazê-las crescer e a ordená-las mais do que a barrá-las, dobrá-las ou destruí-las" (FOUCAULT, 1988, p. 128).

Estaríamos assim diante de um Biopoder o qual Foucault, nesse mesmo texto, nos apresenta duas modalidades distintas e, ao mesmo tempo, complementares de seu exercício: uma que teria como objeto o corpo individual e por princípio o aumento de sua utilidadedocilidade (disciplinas) e outra que teria como objeto a população e por princípio a regulação de seus fenômenos aleatórios (Biopolíticas).

Tratando da primeira modalidade, ou seja, as disciplinas, e considerando-a sobre um primeiro olhar, poderíamos apreciá-las como procedimentos operatórios que teriam por objetivo maior marcar e majorar as forças do corpo sequestrado nas instituições disciplinares num sentido dócil e útil. Assim, teríamos em seu funcionamento, segundo Foucault (2002, p. 117-192), quatro procedimentos:

- Distribuição espacial dos corpos, com as técnicas de:

○ Cercamento; quadriculamento; localização funcional e seriação.

- Controle da atividade, com as técnicas de:

○ horário; elaboração temporal do ato;

○ correlação corpo e gesto; articulação corpo-objeto e utilização exaustiva.

- Organização das gêneses, com as técnicas de:

○ segmentação e sucessão paralela da duração de um ato;

○ organização analítica das seqüências; promoção marcada por exame nas finalizações e desdobramento das séries em outras séries.

- Composição das forças, com os processos de:

○ fixar, mover e articular o corpo singular com outros; ajustar e entrelaçar o tempo dos corpos e criar um sistema preciso de comando.

Como se pode perceber com sua simples listagem, busca-se aí, com toda essa engrenagem criada pelas disciplinas: “[...] concentrar; distribuir no espaço; ordenar no tempo; compor no tempo-espaço uma força produtiva cujo efeito deve ser superior à soma das forças elementares" (DELEUZE, 2000, p. 219) e também, como suplemento, impedir que as trocas 
múltiplas anteriores ao período de trancamento continuem a existir para que o sistema de mando não venha abaixo com a simples comunicação entre os membros do processo.

Os corpos, neste sentido, entram em uma maquinaria que os desarticula, no sentido de apagar seu antigo funcionamento, e os rearticula no sentido de um funcionamento politicamente mais dócil e economicamente mais útil como nos elucida Foucault (2002, p. 119),

A disciplina aumenta as forças do corpo (em termos econômicos de utilidade) e diminui essas mesmas forças (em termos políticos de obediência). Em uma palavra: ela dissocia o poder do corpo; faz dele por um lado uma "aptidão", uma "capacidade" que ela procura aumentar; e inverte por outro lado a energia, a potência que poderia resultar disso, e faz dela uma relação de sujeição estrita. Se a exploração econômica separa a força e o produto do trabalho, digamos que a coerção disciplinar estabelece no corpo o elo coercitivo entre uma aptidão aumentada e uma dominação acentuada.

Não obstante, as operações das disciplinas não se encerram com os procedimentos operatórios. Ainda, se continuarmos com "Vigiar e Punir" encontraremos outras facetas das disciplinas: tratam-se dos recursos mobilizados para que a engrenagem dos procedimentos alcance seu duplo objetivo.

Portanto, neste segundo olhar, encontraremos em jogo no funcionamento das disciplinas como exercício de poder, recursos simples como: vigilância hierárquica; sanção normalizadora e exame.

Nos três recursos trata-se de permitir que tudo o que aconteça nos espaços disciplinares seja objeto para uma informação (vigilância hierárquica), que se imprima em cada corpo enclausurado certo comportamento, conforme a norma a priori de funcionamento das instituições (sanção normalizadora) e, por último, que se anexe ao exercício de poder a criação de saberes sobre aquilo que se encontra encerrado nessas instituições de sequestro e que esses saberes aumentem sua funcionalidade (exame).

Com esses recursos se mobiliza um grande contingente de corpos e impõe-se certa direção para o seu movimento, além de se proporcionar a criação de um reforço do funcionamento das estratégias e táticas de poder por meio do aumento do que se sabe sobre eles.

Uma metáfora arquitetônica serviu a Foucault (2002) de modelo de exposição do funcionamento das disciplinas e também como uma espécie de diagrama de forças que poderia elucidar o funcionamento dos regimes de poder das sociedades ocidentais nesse 
período de sua pesquisa: trata-se do Panópticon de Jeremy Bentham cujo princípio arquitetônico poderia ser descrito como,

[...] na periferia uma construção em anel; no centro, uma torre; esta é vazada de largas janelas que se abrem sobre a face interna do anel; a construção periférica é dividida em celas, cada uma atravessando toda a espessura da construção; elas tem duas janelas, uma para o interior, correspondendo às janelas da torre; outra, que dá para o exterior, permite que a luz atravesse a cela de lado a lado. Basta então colocar um vigia na torre central, e em cada cela trancar um louco, um doente, um condenado, um operário ou um escolar. Pelo efeito da contraluz, pode-se perceber da torre, recortando-se exatamente sobre a claridade, as pequenas silhuetas cativas nas celas da periferia. Tantas jaulas, tantos pequenos teatros, em que cada ator está sozinho, perfeitamente individualizado e constantemente visível (FOUCAULT, 2002, p. 166).

A partir dessa organização arquitetônica, Foucault, pôde descrever certa tendência ao panoptismo na organização do mando em nossas sociedades ocidentais o que o levou a denominá-las, nesse período, disciplinares pelo fato do exercício do poder tornar-se cada vez mais impessoal e abrangente trazendo como corolário a interiorização das normas no corpo dos sujeitos vigiados e punidos.

Não obstante, ao dar continuidade a sua pesquisa sobre os exercícios de poder relacionando-os com a emergência das preocupações modernas em torno da sexualidade, Foucault (1988) pôde perceber que não apenas o corpo individual seria alvo de um tipo de poder que o tomaria no sentido de torná-lo mais dócil e mais útil e, assim, adequando-o à extração da força de trabalho própria do funcionamento das sociedades capitalistas. Outros objetivos próximos a este também fariam parte das relações de poder imanentes às nossas sociedades ocidentais:

[...] a proliferação, os nascimentos e a mortalidade, o nível de saúde, a duração da vida, a longevidade, com todas as condições que podem fazê-los variar; tais processos são assumidos mediante toda uma série de intervenções e controles reguladores (FOUCAULT, 1988, p. 131).

Nestes procedimentos não seria mais o corpo individual o principal alvo dos exercícios de poder, e sim um novo objeto surgido nos escritos de Economia Política do final do século XVIII: trata-se da população. Estaríamos assim diante de uma segunda modalidade do Biopoder: as Biopolítcas da população. Modalidade que Foucault dedicou dois de seus cursos no Collège de France: Segurança, território, população de 1977-1978 e Nascimento da Biopolítica de 1978-1979.

No primeiro dos cursos desse período Foucault (2008, p. 489) buscou traçar a "[...] gênese de um saber político que colocaria no centro de suas preocupações a noção de 
população e os mecanismos suscetíveis de assegurar sua regulação". Neste intuito analisou entre os séculos XV e XVI uma série de tratados que procuravam pensar o exercício de poder em uma forma diversa da soberania.

Como textos principais a encontrar os contrastes, Foucault elegeu "O Príncipe" de Maquiavel como representante do exercício de poder próprio à soberania e o "Miroir politique contenant diverses manières de gouverner" de Guillaume de la Perrière como representante de uma literatura anti-Maquiavel que buscava pensar o exercício de poder assentado em outras bases.

Nesta comparação, os princípios em que se baseava a soberania, entendida no interior das exposições do príncipe de Maquiavel, são contrastadas ponto a ponto a uma certa arte de governar apresentada pelo texto de la Perrière.

Exporemos de forma sucinta o teor destas distinções no quadro abaixo:

\begin{tabular}{|c|c|}
\hline Sober & Arte de Governar \\
\hline $\begin{array}{l}\text { Singularidade e transcendência do } \\
\text { exercício de poder do príncipe em relação aos } \\
\text { súditos. }\end{array}$ & 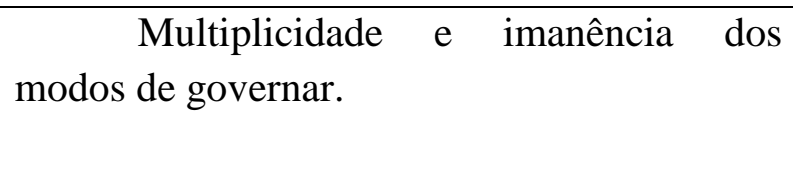 \\
\hline $\begin{array}{l}\text { Descontinuidade entre o poder do } \\
\text { príncipe e as outras formas de poder. }\end{array}$ & $\begin{array}{l}\text { Continuidade ascendente, no sentido } \\
\text { do bom governo do Estado ter como condição } \\
\text { o bom governo de si e da família, e } \\
\text { continuidade descendente, na medida em que } \\
\text { o bom governo do Estado propicia também } \\
\text { um bom governo da família e de si. }\end{array}$ \\
\hline $\begin{array}{l}\text { Coisas sobre as quais se exerce o } \\
\text { poder limitam-se ao território e seus } \\
\text { habitantes. }\end{array}$ & $\begin{array}{l}\text { Exerce-se o poder sobre um conjunto } \\
\text { de homens e coisas. Sendo que, o termo } \\
\text { coisas adquire um sentido amplo abarcando } \\
\text { desde as riquezas, os recursos etc; os } \\
\text { costumes, os hábitos, as formas de agir e } \\
\text { pensar até as desgraças como a fome a } \\
\text { epidemia e a morte. }\end{array}$ \\
\hline $\begin{array}{l}\text { Finalidade do exercício do poder } \\
\text { assenta-se sobre a obediência da lei soberana. } \\
\text { Finalidade circular, portanto. }\end{array}$ & $\begin{array}{l}\text { Finalidade imanente às coisas a serem } \\
\text { dirigidas procurando a perfeição, } \\
\text { intensificação dos processos e dos } \\
\text { instrumentos de governo por meio de táticas } \\
\text { diversas. }\end{array}$ \\
\hline $\begin{array}{l}\text { Exercício do poder marcado pelo uso } \\
\text { da força e da violência. }\end{array}$ & $\begin{array}{l}\text { Busca da sabedoria - entendida no } \\
\text { sentido do conhecimento das coisas e dos } \\
\text { súditos - e da paciência - entendida no }\end{array}$ \\
\hline
\end{tabular}




\begin{tabular}{|l|l|}
\hline & $\begin{array}{l}\text { sentido do soberano se por a serviço dos } \\
\text { súditos - como marcas principais no } \\
\text { exercício do poder. }\end{array}$ \\
\hline
\end{tabular}

Quadro 1 - Soberania versus Arte de Governar.

Fonte: FOUCAULT, Michel. Segurança, território, população. São Paulo: Martins Fontes, 2008, p. 117-153.

A tensão principal que Foucault apreende nesta literatura anti-Maquiavel surgida entre os séculos XV e XVI é uma tentativa de trazer para o nível da gestão do Estado, os princípios de governo que eram utilizados na gestão da família, que, neste período se conhecia pelo termo economia entendido como uma série de procedimentos que permitiam ao pai bem governar tanto os membros da família quanto suas propriedades e os seus recursos.

Esta arte de bem governar o Estado, seria então encarar o seu governo a partir do modelo da família, problema que Foucault (2008, p. 126-127) retira dos textos de Rousseau,

[...] a palavra economia designa originalmente o sábio governo da casa para o bem comum de toda a família. Problema, diz Rousseau: como esse sábio governo da família poderá, mutatis mutandis, e com as descontinuidades que serão observadas, ser introduzido na gestão geral do Estado? Governar um Estado será, portanto, aplicar a economia, uma economia no nível de todo o Estado, isto é, ter em relação aos habitantes, às riquezas, à conduta de todos e de cada um uma forma de vigilância, de controle, não menos atenta do que a do pai de família sobre a casa e seus bens.

Nesta perspectiva, o mercantilismo, para Foucault, foi uma primeira tentativa de se pensar uma arte de governo do Estado se utilizando dos princípios de governo familiares. Porém, ao arrastar esse modelo familiar para dentro das estruturas do modelo soberano, o mercantilismo fracassara como arte de governo, principalmente por se utilizar dos mesmos instrumentos que a soberania se utilizava, ou seja, as leis; e também por tentar buscar a mesma finalidade do exercício de poder soberano, ou seja, o governo do território para a constituição de riquezas e poderio para o soberano,

[...] o mercantilismo viu-se bloqueado e detido, creio eu, precisamente por ter se dado o que como objetivo? Pois bem, essencialmente o poder do soberano: como fazer de modo que não tanto o país seja rico, mas para que o soberano possa dispor de riquezas, posa ter tesouros, que possa constituir exércitos com os quais poderá fazer a sua política? O objetivo do mercantilismo é o poder do soberano, e os instrumentos que o mercantilismo se dá, quais são? São as leis, os decretos, os regulamentos, isto é, as armas tradicionais da soberania (FOUCAULT, 2008, p. 136).

Destarte, só em fins do século XVII e início do século XVIII que se iniciou um desbloqueio desta arte de governar em relação à soberania o que a levaria a ser substituída pela Economia Política. Alguns fatores, relata Foucault (2008), intervieram neste desbloqueio 
no decorrer do século XVII entre eles: a expansão demográfica; a abundância monetária resultada da incursão dos metais preciosos das colônias e o aumento da produção agrícola.

Não obstante, todos esses fatores giraram a partir da explicitação do problema da população, ou seja, quando se começou a pensar em uma forma de governar esse conjunto de elementos instáveis, porém, passíveis de intervenção é que se tornou possível a experimentação de uma forma de governo que não mais fosse refém do modelo jurídico da soberania.

A forma de governo então que tomou como alvo a população e seus efeitos instáveis foi a Economia Política entendida tanto como disciplina de saber quanto técnica de governo própria a um nível de realidade designado economia,

[...] a economia política pôde se constituir a partir do momento em que, entre os diversos elementos da riqueza, apareceu um novo objeto, a população. Apreendendo a rede de relações contínuas e múltiplas entre a população, o território, a riqueza, etc., se constituirá uma ciência que se chamará economia política, e ao mesmo tempo um tipo de intervenção característico do governo: a intervenção no campo da economia e da população. Em suma, a passagem de uma arte de governo para uma ciência política, de um regime dominado pela estrutura da soberania para um regime dominado pelas técnicas de governo, ocorre no século XVIII em torno da população e, por conseguinte, em torno do nascimento da economia política (FOUCAULT, 2008, p. 140-141).

Portanto, Foucault, ao transitar pela falência do modelo de exercício de poder soberano e pela sua substituição por um outro, elaborou uma genealogia do Estado Moderno observando três momentos específicos em sua constituição:

[...] em primeiro lugar, o Estado de justiça, nascido em uma territorialidade de tipo feudal e que corresponderia grosso modo a uma sociedade da lei; em segundo lugar, o Estado administrativo nascido em uma territorialidade de tipo fronteiriço nos séculos XV-XVI e que corresponderia a uma sociedade de regulamento e de disciplina; finalmente, um Estado de governo que não é mais essencialmente definido por sua territorialidade, pela superfície ocupada, mas pela massa da população, com seu volume, sua densidade, e em que o território que ela ocupa é apenas um componente (FOUCAULT, 2008, p. 145).

E é neste sentido de apreensão do funcionamento do modo de governo do Estado Moderno que ele elaborou o conceito de governamentalidade entendendo-o como,

[...] conjunto constituído pelas instituições, procedimentos, análises e reflexões, cálculos e táticas que permitem exercer esta forma bastante específica e complexa de poder, que tem por alvo a população, por forma principal de saber a economia política e por instrumentos técnicos essenciais os dispositivos de segurança (FOUCAULT, 2008, p. 143). 
Identificando a Economia Política como a forma principal de saber que funcionou no Estado Moderno como o sustentáculo dos cálculos e maneiras de geri-lo no sentido do investimento político sobre a majoração de suas forças; Foucault dedicou o curso do ano seguinte $^{4}$ ao estudo do desenvolvimento desta disciplina de saber e prática de governo.

Realizou assim um estudo rigoroso do Liberalismo em suas principais fases tendo o cuidado de o entender,

[...] não como uma teoria, nem como uma ideologia e, ainda menos, como um modo de a "sociedade se representar", mas como uma prática, como uma "maneira de fazer" orientada para objetivos e se regulando através de uma reflexão contínua. O Liberalismo deve ser analisado, então, como princípio e método de racionalização do exercício de governo - racionalização que obedece, e aí está sua especificidade, à regra interna da economia máxima (FOUCAULT, 2004, p. 324).

Uma das principais características do funcionamento do Liberalismo como prática de governo, levantada por Foucault, trata-se do mesmo fundar-se na questão que sempre se governa demais, ou seja, é preciso haver algo que justifique a existência de um aparelho de governo que tenha seu fim distanciado si próprio. Neste sentido, o Estado, dentro da perspectiva liberal, não pode encontrar em si mesmo a justificativa de sua existência; ele deve existir para servir a outra coisa que não ele mesmo.

Dessa maneira o Liberalismo cria a sociedade civil como aquilo que justificaria e sustentaria os investimentos de governo do Estado. Em outras palavras, se existe Estado é para que ele sirva à sociedade civil e sempre a atuação daquele sobre esta deve ser vista com a desconfiança de ser excessiva.

Entre as correntes que esta prática de governo possuiu do século XVIII ao nosso presente, Foucault observou somente diferenças de perspectiva. No Liberalismo Clássico, essa possibilidade de atenuar-se cada vez mais o governo da sociedade civil pelo Estado assentavase no credo de que os indivíduos eram naturalmente materialistas e individualistas, ou seja, não haveria a necessidade de um governo excessivo da sociedade civil porque naturalmente os indivíduos buscavam satisfazer suas necessidades por meio de um aumento de suas riquezas constituído a partir de uma atividade individual e nesse percurso a sociedade civil se organizaria por si própria extinguindo a necessidade de um governo demasiado por meio do Estado.

\footnotetext{
${ }^{4}$ FOUCAULT, Michel. Naissance de la biopolitique. Paris: Gallimard Seuil, 2004.
} 
Porém, no Neoliberalismo, após a comprovação histórica de que a ação descontrolada das atividades econômicas individuais não levaram a um conjunto harmônico da sociedade civil $^{5}$, tomou-se como artifício esta possibilidade do individualismo e do materialismo figurarem como modos de constituição dos componentes da sociedade civil.

Neste sentido, na perspectiva do Neoliberalismo - em especial o da Escola de Chicago - segundo Foucault (2004), o sujeito materialista e individualista que garantiria a mínima interferência do Estado deveria ser produzido para que fosse possível uma organização quase autônoma da sociedade civil; o que o faz alastrar suas práticas, na tentativa dessa produção, a domínios bem distintos do econômico.

E, tal perspectiva é bem explicitada quando Foucault (2004, p. 329) descreve os princípios de funcionamento desse Neoliberalismo da Escola de Chicago que,

[...] busca estender a racionalidade do mercado, os esquemas de análise que ela propõe e os critérios de decisão que sugere a domínios não exclusivamente ou não prioritariamente econômicos. No caso, a família e a natalidade ou a delinquiência e a política penal.

Aqui talvez Foucault já deixe claro que a perspectiva do Neoliberalismo não se limita a um esvaziamento das operações do Estado por meio da extinção de seus serviços atuantes no governo da sociedade civil, pelo contrário, o que marca o exercício dessa estratégia de poder é alastrar-se pela sociedade civil produzindo essas individualidades que promovam a mínima interferência do Estado. Tal estratégia de governo, portanto, toma a matriz mercadológica entendida como lócus de veridicção ${ }^{6}$ e a alastra por espaços os mais capilares possíveis da sociedade civil como uma espécie de comandos operadores do uso de si das singularidades produzidas nessa sociedade. Produz e consome liberdades regulando por meio dos dispositivos de segurança ${ }^{7}$ as crises de governamentalidade sempre presentes em suas frágeis estratégias de governo.

\footnotetext{
${ }^{5}$ Com a crise de 1929 ficou claro que a perspectiva de Adam Smith da mão invisível não era passível de comprovação em virtude das ações individuais dos capitalistas terem guiado a economia mundial a uma crise nunca antes vista.

${ }^{6}$ Veridicção entendida como lócus de produção de verdade.

${ }^{7}$ Conceito desenvolvido no curso "Segurança, Território, População" ministrado no Collège de France entre os anos 1977 e 1978 para distinguir o funcionamento das disciplinas e das biopolíticas. Nesse curso Foucault apresenta algumas distinções entre os mecanismos disciplinares e os dispositivos de segurança que podemos resumir assim: os mecanismos disciplinares funcionariam em espaços fechados, teriam um público restrito e aplicariam sobre ele uma norma a priori; os dispositivos de segurança funcionariam em espaços abertos, teriam por alvo uma população indiferenciada e tentariam tirar dos fenômenos próprios a ela uma norma a posteriori no intuito de gestá-los em uma curva de normalidade. Exames escolares são exemplos de mecanismos disciplinares e campanhas de vacinação são exemplos de dispositivos de segurança.
} 
Com esses dois cursos de Foucault fica clara a organização das Biopolíticas em torno da arte de governar liberal, inscrita em seu momento contemporâneo no que conhecemos por neoliberalismo.

Conceituada, assim, a primeira fase de nossa investigação apresentaremos, no decorrer do texto, duas perspectivas sobre a transição do pensamento de Foucault entre a problematização do Biopoder e a busca de exercícios de constituição de si que tivessem por princípio a liberdade de adesão. Fazemos isso com o intuito de esclarecer um pouco um transitar, a princípio radical, entre a descrição de meios de intervenção-tutela e maneiras de livre constituição que marcaram os oitos anos de silêncio entre a publicação do primeiro volume da história da sexualidade (A vontade de saber - 1976) e os dois últimos volumes (Uso dos prazeres e Cuidado de si - 1984).

\section{Transição}

Temos a respeito dessa transição duas hipóteses distintas: a de crise-ruptura apresentada por Gilles Deleuze e a de lenta mutação apresentada por Frederic Gros.

Deleuze (2000) apreende o pensamento de Foucault funcionando por meio de crises e rupturas. É assim que ele percebe a descoberta das relações de poder sobre os extratos de saber na virada entre as obras Arqueologia do Saber e Vigiar e Punir e também a descoberta dos modos de subjetivação como dobramento da linha do fora entre os extratos do saber e do não estratificado das relações de poder durante o silêncio de oito anos entre o primeiro e o segundo volume da História da Sexualidade.

Comentando seu livro sobre Foucault ${ }^{8}$, Deleuze diz que todo grande pensador possui essa problemática quando se trata de lidar com o pensamento. Fala então de uma linha por meio da qual se pode pensar e viver ${ }^{9}$. Em sua visão Foucault teria habitado intensamente os movimentos dessa linha e, essas reviravoltas de seu pensamento corresponderiam a reviravoltas simultâneas em sua vida. É assim que ele vê a aparição das relações de poder no pensamento de Foucault como correlatos ao envolvimento do filósofo no maio de 1968 e também de sua investida no GIP ${ }^{10}$ no pós-maio de 1968.

Contudo, esse momento também marcaria um impasse, não necessariamente do seu pensamento, mas um impasse do filósofo em relação ao próprio poder. Deleuze diz que pareceria que Foucault sentisse-se preso às relações de poder. Como se tudo que se pensasse,

\footnotetext{
${ }^{8}$ DELEUZE, Gilles. Foucault. 2. ed. São Paulo: Brasiliense, 1991.

${ }^{9}$ Linha do fora.

${ }^{10}$ Grupo de Informação sobre as prisões.
} 
tudo que se falasse, tudo que se vivesse acontecesse por meio de um choque com o poder, e para retratar isso buscou uma frase de um texto de Foucault (2003, p. 208) sobre a vida dos homens infames que data desse período,

[...] sempre a mesma incapacidade de ultrapassar a linha, de passar para o outro lado, de escutar e fazer ouvir a linguagem que vem do outro lugar ou de baixo; sempre a mesma escolha, do lado do poder, do que ele diz ou do que ele faz dizer [...]. Afinal, não é um dos traços fundamentais de nossa sociedade o fato de que nela o destino tome a força da relação com o poder, da luta com ou contra ele? O ponto mais intenso das vidas, aquele em que se concentra sua energia, é bem ali onde elas se chocam com o poder, se debatem com ele, tentam utilizar suas forças ou escapar de suas armadilhas.

Para Deleuze seria então necessidade vital do pensamento de Foucault operar uma ruptura, ultrapassar a linha e descobrir os modos de subjetivação como maneiras singulares de dobrar as forças do fora em exercícios práticos de si: ou operava-se essa ruptura ou parava-se de escrever. E, para isso, foi necessário operar um deslocamento de seu projeto original da história da sexualidade que ainda procederia em relação ao seu método anterior de identificar os enunciados em torno da sexualidade e suas relações com os diagramas de poder, vendo aí as produções subjetivas e os focos de resistência. Tudo isso em períodos históricos curtos, no caso, o transitar entre o século XVII e o século XIX como fora até então em seus livros anteriores.

Gros (2004), diferentemente de Deleuze, ao acompanhar os cursos de Foucault no Collège de France no decorrer da década de 1980, observa em vez de uma ruptura, uma lenta mutação no pensamento do filósofo embasada na percepção de uma continuidade que se daria no sentido da busca de uma problematização do sujeito que estivesse fundada em uma relação de liberdade e não em uma relação estrita de obediência ao observar o desenrolar dos desenvolvimentos teóricos apresentados por Foucault no decorrer dos cursos de 1979-1980 (O Governo dos Vivos); 1980-1981 (Subjetividade e Verdade) e 1981-1982 (A Hermenêutica do Sujeito).

Foucault, na visão de Gros, não teria encontrado essa possibilidade de constituição do sujeito em uma relação de liberdade entre os séculos comuns de suas pesquisas (XVII-XIX), daí fazer um retorno à experiência cristã, na qual identifica o iniciar-se de nossa relação de obediência para com a verdade, e, por fim, um retorno aos gregos ${ }^{11}$.

\footnotetext{
${ }^{11} \mathrm{O}$ termo retorno não deve ser entendido aqui como uma tentativa de Foucault trazer para o presente de sua pesquisa a experiência grega, no caso, adotar o modelo grego como uma possibilidade presente. O que ele busca é a partir das questões levantadas pelos gregos analisarmos as questões que nos propomos hoje como constituintes de nossos modos de vida contemporâneos.
} 
Portanto, não seria um impasse ou uma ruptura que marcaria o silêncio de oito anos entre a Vontade de Saber e o Uso dos prazeres e sim uma lenta mutação do pensamento de Foucault em busca de uma problematização do sujeito moderno que escapasse às relações de sujeição-obediência que ele havia descrito nos estudos sobre o complexo saber-poder e que a relação diretor de consciência-dirigido, oriunda da pastoral cristã, pareceria figurar como ponto inicial.

\section{0 cuidado de si e suas possibilidades no modo de vida contemporâneo}

Elucidadas as duas primeiras partes de nossa pesquisa, que trataram da apresentação do que Foucault pensava por Biopoder e o que se operou em seu pensamento na transição que marca seus últimos escritos, partiremos, num exercício final operado sobre seu pensamento, de extrair como suas problematizações acerca do cuidado de si poderiam nos auxiliar em nossa constituição como seres éticos e, para isso, nos concentraremos nas três primeiras aulas do curso A Hermenêutica do Sujeito ${ }^{12}$ pronunciado por Foucault em 1982.

Na primeira hora da aula de seis de janeiro, Foucault apresenta a problemática geral do curso assim como marca a premência do cuidado de si em relação ao conhece-te a si mesmo no pensamento antigo além de ilustrar o movimento que fez da segunda fórmula a mais significativa para a experiência do sujeito ocidental moderno.

Na segunda hora da aula inicia-se, por meio do texto sobre o diálogo de Sócrates com Alcibíades $^{13}$, a apreensão do cuidado de si no interior da cultura grega; problema que continuará a ser detalhado no decorrer de toda a aula de 13 de janeiro. Por fim, na aula de 20 de janeiro será detalhado o deslocamento dessa fórmula para a cultura romana dos dois primeiros séculos de nossa era.

Nessas aulas Foucault percebe que na Grécia do século IV antes de Cristo o cuidado de si funcionava como uma série de exercícios necessários ao jovem aristocrata se o mesmo desejasse ocupar um local de destaque na vida política da Polis. É assim que Alcibíades é inquirido por Sócrates em seu diálogo. E, nesse aspecto, a fórmula acumularia as funções de: despertar do estado de ignorância, e nesse sentido é apresentada uma crítica à pedagogia do jovem ateniense; preparo para o governo dos outros, no caso, desenvolvimento de uma técnica de si que superasse a defasagem do preparo do jovem ateniense em relação aos seus

\footnotetext{
${ }^{12}$ FOUCAULT, Michel. A hermenêutica do sujeito. São Paulo: Martins Fontes, 2004.

${ }^{13}$ Alcebíades é destacado nesse diálogo com Sócrates por tratar-se da promessa política de Atenas. Alcebíades era belo, filho da aristocracia ateniense e preparava-se para ocupar cargo político de destaque na Polis.
} 
adversários políticos ${ }^{14}$ e cultivo da alma, no sentido de que o si que se cuidava não se tratava nem dos bens e nem do corpo, e sim, da alma.

Todas essas funções do cuidado de si na Grécia Clássica estariam então circunscritas aos jovens aristocratas que desejassem ocupar um papel político proeminente no interior da Polis. Não se tratava, assim, de uma fórmula co-extensiva a todos os motivos, a todos os cidadãos gregos e a todas as faixas etárias. A força que impulsionaria o cuidado de si estaria restrita a uma busca do governo político sobre os demais cidadãos da Polis e também se vincularia tão somente aos jovens aristocratas.

Quando a fórmula é apropriada pela filosofia helenística e romana ${ }^{15}$, algumas modificações serão percebidas em relação à idade de quem faria uso da mesma e também em relação aos motivos de tal uso. No período helenístico e iniciar-se do período romano o cuidado de si tornou-se utilizável durante todo o período da vida; não era mais restrita aos jovens. Também não era mais privilégio dos que buscavam o poder político; tornou-se algo que permitia um enfrentamento mais tranqüilo em relação à tragédia própria dos viventes.

Duplo deslocamento, portanto: em relação à idade do sujeito que faria uso e em relação ao objeto buscado por meio do uso, no caso, deixa de ser o poder político e passa a ser uma busca de serenidade. Contudo, apesar das diferenças quanto ao sujeito e ao objeto do cuidado de si em seu transitar da Grécia Clássica aos dois primeiros séculos de nossa era, uma coisa, continuou constante: a liberdade de aderência ou não ao conjunto de regras que compunha tal atitude.

E é a isso que Foucault se agarra para explicitar que nossas possibilidades de constituição, no presente, estão sujeitas a um código moral cuja aderência não é pensada do lado do sujeito que pratica o código e sim exigida do lado de alguma instituição que compõe o tecido social.

E pensando nas contribuições desses estudos quando o que procuramos é nos constituirmos como seres éticos em oposição a um sujeito moral dado, talvez pudéssemos afirmar que: se o que somos é resultado de uma série de exercícios em que dosamos relações de força com nós mesmos, relações de força com as instituições e relações de verdade com as práticas inerentes aos saberes, então, não existe em nós algo dado de antemão e que pode ser

\footnotetext{
${ }^{14}$ Os adversários seriam os jovens espartanos e os jovens persas. A Cidade-Estado Esparta e o Reino da Pérsia encontravam-se em conflito político com a Cidade-Estado Atenas nesse período, no caso, o século IV A.C.

${ }^{15}$ Foucault concentrou-se nos textos dos estóicos e ocasionalmente dos epicuristas para problematizar a estrutura subjetiva designada como cuidado de si nos dois primeiros séculos de nossa era. Mereceram principal atenção os textos de Sêneca, Marco Aurélio, Epíteto e Epicuro.
} 
revelado em uma experiência de submissão, e sim que podemos nos constituir e nos modificar caso tenhamos a coragem necessária para transgredirmos todas essas instâncias que pretendem nos governar. Nesse sentido, o que somos apareceria como um movimento violento a partir do qual dobraríamos a linha do fora num espaço subjetivo marcado pelas relações de poder-saber ${ }^{16}$.

Essa maneira em lidar com a vida é bem explicitada em um dos últimos textos de Foucault ${ }^{17}$ quando o mesmo, em uma leitura crítica de um texto de Kant sobre a modernidade, a toma não como um período histórico e sim como uma atitude que temos de tomar se o que desejamos é o uso livre de nossa razão, e o uso livre de nossa razão significa abandonarmos a segurança das tutelas que historicamente nos seduzem a uma servidão voluntária e tatearmos o difícil jogo impaciente e arriscado da liberdade. Essa bela passagem do texto explicita essa inquietação,

Não sei se algum dia nos tornaremos maiores. Muitas coisas em nossa
experiência nos convencem de que o acontecimento histórico da Aufklärung
não nos tornou maiores; e que nós não o somos ainda. Entretanto, parece-me
que se pode dar um sentido a essa interrogação crítica sobre o presente e
sobre nós mesmos formulada por Kant ao refletir sobre a Aufklärung.
Parece-me que esta é, inclusive, uma maneira de filosofar que não foi sem
importância nem eficácia nesses dois últimos séculos. É preciso considerar a
ontologia crítica de nós mesmos não certamente como uma teoria, uma
doutrina, nem mesmo como um corpo permanente de saber que se acumula;
é preciso concebê-la como uma atitude, um êthos, uma via filosófica em que
a crítica do que somos é simultaneamente análise histórica dos limites que
nos são colocados e prova de ultrapassagem possível. [...] Não sei se é
preciso dizer hoje que o trabalho crítico também implica a fé nas Luzes; ele
sempre implica, penso, o trabalho sobre nossos limites, ou seja, um trabalho
paciente que dá forma à impaciência da liberdade (FOUCAULT, 2005, p.
351).

Mesmo que difícil, problemática, arriscada e talvez fugaz, essa seria a contribuição desses estudos de Foucault para a construção de nossas subjetividades no contemporâneo: uma luta constante em busca de um sopro de liberdade em meio a uma instrumentalização e programação cada vez mais crescentes da vida.

\footnotetext{
${ }^{16}$ Uma descrição mais detalhada desse movimento pode ser encontrada em: DELEUZE, Gilles. Foucault. São Paulo: Brasiliense, 1988. No capítulo intitulado "As dobras ou o lado de dentro do pensamento (subjetivação)" é apresentada uma descrição detalhada assim como um diagrama ilustrativo. Tratamos mais detalhadamente desse diagrama em: AMBRÓZIO, A.; BONILHA FILHO, R.. Liberalismo-cidadania = Império-empresariamento da vida. In: III Congresso Internacional e IX Semana de Psicologia: Coletividade e Subjetividade na Sociedade Contemporânea, 2007, Maringá - PR. Anais do III Congresso Internacional e IX Semana de Psicologia: Coletividade e Subjetividade na Sociedade Contemporânea, 2007.

${ }^{17}$ FOUCAULT, Michel. O que são as luzes. In: FOUCAULT, Michel. Ditos e Escritos II: arqueologia das ciências e história dos sistemas de pensamento. 2. ed. Rio de Janeiro: Forense Universitária, 2005.
} 


\section{Referências}

AMBRÓZIO, A.; BONILHA FILHO, R. Liberalismo-cidadania: Império-empresariamento da vida. In: (Anais) III Congresso Internacional e IX Semana de Psicologia: Coletividade e Subjetividade na Sociedade Contemporânea, 2007.

DELEUZE, Gilles. Foucault. São Paulo: Brasiliense, 1988.

. Um retrato de Foucault. In: DELEUZE, Gilles. Conversações. Rio de Janeiro: Editora 34, 2000.

Post-scriptum sobre as sociedades de controle. In: DELEUZE, Gilles. Conversações. Rio de Janeiro: Editora 34, 2000.

FOUCAULT, Michel. O pensamento do exterior. In: Ditos e escritos III: estética: literatura e pintura, música e cinema. Rio de Janeiro: Forense Universitária, 2001. A vida dos homens infames. In: Ditos e escritos IV: estratégia, poder-saber. Rio de Janeiro: Forense Universitária, 2003.

. O que são as luzes. In: FOUCAULT, Michel. Ditos e Escritos II: arqueologia das ciências e história dos sistemas de pensamento. 2. ed. Rio de Janeiro: Forense Universitária, 2005.

História da sexualidade I: a vontade de saber. 14. ed. Rio de Janeiro: Edições Graal, 2001.

Vigiar e punir. 25. ed. Petrópolis: Vozes, 2002.

História da sexualidade 2: o uso dos prazeres. 9. ed. Rio de Janeiro: Graal, 2001.

História da sexualidade 3: o cuidado de si. 7. ed. Rio de Janeiro: Graal, 2002.

. Securité, territoire, population. Paris: Gallimard Seuil, 2004.

. Segurança, território, população. São Paulo: Martins Fontes, 2008.

Naissance de la biopolitique. Paris: Gallimard Seuil, 2004.

A hermenêutica do sujeito. São Paulo: Martins Fontes, 2004.

GROS, Frédéric. Situação do curso. In: FOUCAULT, Michel. A hermenêutica do sujeito. São Paulo: Martins Fontes, 2004. 